\title{
Audit to evaluate preoperative visit to patient by anaesthetist
}

\author{
Ganeshanathan Vyhunthan', N.G. Aeshana de Silva ${ }^{2}$ \\ Senior Registrar ${ }^{1}$ in Anaesthesiology, Medical Officer ${ }^{2}$ in Anaesthesia and Intensive care, District \\ General Hospital Mannar, Sri Lanka.
}

*Corresponding Author: drganesh0777@gmail.com

\begin{abstract}
Pre operative assessment is an important component of anaesthesia. This remains the most efficient and accurate way of initially detecting significant morbidity. Patient satisfaction is an essential achievement when receiving general anaesthesia. The aim of this audit was to identify whether patients were satisfied with the preoperative anaesthetic assessment. Of the 300 patients audited $95 \%$ were seen by an anaesthetist before surgery. Preoperative instructions, fasting instructions were given to $94.39 \%$, while only $42.1 \%$ of the patients were aware of the type of anaesthesia prior to surgery. $35.44 \%$ received an explanation from the anaesthetist regarding modes of post operative analgesia, and $94.38 \%$ of the patients had a percentage satisfaction of more than $50 \% .90 .88 \%$ of the patients were satisfied regarding the time spent with them prior to surgery. Patient's questions were answered only on $83.86 \%$ of the occasions. $96.14 \%$ of the patients were relaxed following the pre operative visit.
\end{abstract}

Key words: preoperative, assessment, instructions

Pre operative and post operative anxiety, post operative pain and post operative complications are decreased in subjects who receive information regarding their anaesthetic and surgery. Factual knowledge of anaesthesia improves compliance with perioperative instructions and facilitates informed consent.

Good pre-operative assessment and screening enable identification of all essential resources and obstacles to discharge for patients, and thereby minimize late cancellation of operations, assisting overall patient care and efficiency of operating lists. ${ }^{1}$

History and examination performed by appropriately trained and competent personnel remains the most efficient and accurate way of initially detecting significant morbidity.

Missing a day of work causes reduced income and unnecessary travel expenses, wastage of time and effort. This has a major impact for low income communities. Additional testing and new appointments add to this burden, while patient disappointment and frustration are also major problems.

Complications and malpractice lawsuits are often attributable to poor preparation and failure in communication. Essential team members include anaesthetists, surgeons, physicians and general practitioners. Specialist anaesthetic preoperative assessment nurses have been shown to be safe and effective at pre-operative screening and should be an integral part of the team. ${ }^{2}$

The visit to a pre-operative clinic gives the patients an opportunity to discuss the choices of anaesthetic technique, methods for pain relief and the risks, in a calmer atmosphere than immediately before the operation. ${ }^{3}$

This audit aims to seek answers to the following questions.

1. To identify whether pre operative assessment was done by the anaesthetist.

2. To identify whether pre operative instructions were given by the anaesthetist

3. To identify whether patient was satisfied with the pre operative anaesthetic assessment.

\section{Methodology}

The audit was conducted in District General Hospital, Mannar in the northwestern province of Sri Lanka. Patients were interviewed by an anaesthetic medical officer, who was not involved in the patient's pre operative anaesthetic assessment, within the first post 
operative day, in the ward. We maintained the patient's privacy and anonymity, as far as possible. Patients undergoing elective, casualty and emergency surgeries from surgical unit and gynaecology and obstetrics unit from 1/7/2011 to 30/7/2011 were included. Both males and females of all ages were included. Patients undergoing surgery for more than once during the above period were taken as a single entity. Patients who received $1^{\text {st }} 24$ hour post operative care at ICU/HDU were not included. Sample size was estimated by reviewing a similar study done in Sri Lanka. ${ }^{4}$ The study instrument was an interviewer administered questionnaire. The questions were based on previous similar studies, guidelines from the UK, Sri Lankan guidelines and discussions held among the authors. All the questions were asked in tamil which is the language used by the population. Sinhalese was used for those of whom it was the first language. Ethical clearance was obtained from the ethical review committee of the National Hospital of Sri Lanka as such a committee was not formed at the Mannar Hospital. Informed verbal consent was obtained from all subjects participating in the study after explaining the objectives and necessities of the study. Privacy and confidentiality of data was preserved. Role plays were held among the authors to ensure that data collection would be conducted in a uniform and accurate manner. Pretesting of the questionnaire was done among 10 patients to ensure validity, reliability and clarity of the questionnaire. These patients were not included in the study population.

\section{Results}

Table 1: Age distribution of study population

\begin{tabular}{|lll|}
\hline Age & Frequency & $\%$ \\
\hline$<12$ Years & 39 & 13 \\
12-20 Years & 20 & 6.7 \\
21-40 Years & 160 & 53.3 \\
41-60 Years & 61 & 20.3 \\
>60 Years & 20 & 6.7 \\
Total & 300 & 100 \\
\hline
\end{tabular}

Table 2: Type of Surgery

\begin{tabular}{|lll|}
\hline Type of surgery & Frequency & $\%$ \\
Major & 165 & 55 \\
Minor & 135 & 45 \\
Total & 300 & 100 \\
\hline
\end{tabular}

Pre Operative Assessment

Table 3 : Patient history taken by Anaesthetist

\begin{tabular}{|lll|}
\hline & Frequency & $\%$ \\
Yes & 285 & 95 \\
No & 15 & 5 \\
Total & 300 & 100 \\
\hline
\end{tabular}

Table 4 : Self Introduction done by anaesthetist

\begin{tabular}{|lll|}
\hline & Frequency & $\%$ \\
Yes & 154 & 54.03 \\
No & 131 & 45.96 \\
Total & 285 & 100 \\
\hline
\end{tabular}

Pre operative instructions

Table 5: Fasting Instructions

\begin{tabular}{|lll|}
\hline & Frequency & $\%$ \\
Yes & 269 & 94.39 \\
No & 16 & 5.6 \\
Total & 285 & 100 \\
\hline
\end{tabular}

Table 6 : Awareness of type of anaesthesia before surgery

\begin{tabular}{|lll|}
\hline & Frequency & $\%$ \\
Yes & 120 & $42 . .1$ \\
No & 165 & 57.9 \\
Total & 285 & 100 \\
\hline
\end{tabular}

Table 7 : Anaesthetist explained modes of post operative analgesia

\begin{tabular}{|lll|}
\hline & Frequency & $\%$ \\
Yes & 101 & 35.44 \\
No & 184 & 64.56 \\
Total & 285 & 100 \\
\hline
\end{tabular}

Satisfaction of pre operative anaesthetic assessment

We assessed the overall satisfaction of the patient, about the pre operative visit by the anaesthetist. To get the quantitative value, percentage satisfaction was considered. On a scale from $0 \%$ to $100 \%$, percentage patient satisfaction was inquired as to whether less than $50 \%$ or more than $50 \%$.

Table 8: Satisfaction regarding preoperative visit by the anaesthetist

\begin{tabular}{|lll|}
\hline & Frequency & Percentage \\
$0-50 \%$ & 16 & 5.61 \\
$50-100 \%$ & 269 & 94.38 \\
Total & 285 & $100 \%$ \\
\hline
\end{tabular}


Table 9: Time duration allocated to patient in the anaesthetists pre op visit

\begin{tabular}{|lll|}
\hline & Frequency & $\%$ \\
Adequate & 259 & 90.88 \\
Inadequate & 26 & 9.12 \\
Total & 285 & 100 \\
\hline
\end{tabular}

Table 10: Adequacy of answering questions by anaesthetist

\begin{tabular}{|lll|}
\hline & Frequency & $\%$ \\
Answered poorly & 239 & 83.86 \\
Answered well & 46 & 16.14 \\
Total & 285 & 100 \\
\hline
\end{tabular}

Table 11: Relief of anxiety following visit by anaesthetist

\begin{tabular}{|lll|}
\hline & Frequency & $\%$ \\
Relaxed & 274 & 96.14 \\
Not relaxed & 11 & 3.86 \\
Total & 285 & 100 \\
\hline
\end{tabular}

\section{Discussion}

Patients were interviewed by a medical officer in anaesthesia, who was not involved in the patient's pre operative anaesthetic assessment, within the first post operative day, in the ward. This was to avoid bias towards the study from the involved parties. Majority of our patients represented the young age group (more than $50 \%$ ). (Table 1) One reason for this is that patients warded for elective, casualty and emergency surgeries were included and did not define a lower limit to the age group. When we consider hospital statistics, there were higher number of minor surgeries when compared to that of major category, but in our study population that difference was not very significant. (Table 2) Patient history was taken by the anaesthetist on $95 \%$ of the occasions. (Table 3) The anaesthetist introduced him/herself to the patient only in $54.03 \%$ of occasions (Table 4). Fasting instructions were given to $94.39 \%$ of the patients (Table 5). Only $42.1 \%$ of the patient's were aware of the type of anaesthesia that would be used on them prior to surgery (Table 6). Only $35.44 \%$ of the patients received an explanation regarding modes of post operative analgesia from the attending anaesthetist (Table 7). All these figures are less than $100 \%$, which is the recommended figure by the Royal College of Anaesthetists (RCoA).
The reason for this probably is the high work load and limited cadre of trained anaesthetists in Mannar Hospital.

Only $94.38 \%$ of the patient's had a percentage satisfaction of more than $50 \%$ of the pre operative visit done by the anaesthetist (Table 8 ). More than $50 \%$ of those who were satisfied had a satisfactory level above their expectations. Patients who had major surgery had a low level of satisfaction.

$90.88 \%$ of the patients were satisfied regarding the time spent by the anaesthetist with the patient prior to surgery (Table 9), Questions patient had were answered by an anaesthetist on $83.86 \%$ of the occasions (Table 10). This is well below $100 \%$, which is the recommended figure by the Association of Anaesthetists of Great Britain and Ireland (AAGBI). ${ }^{2}$ This is probably due to the fact that patient care is divided (preoperative visit and anaesthesia performed by two different anaesthetists) and unexpected case cancellations. The study showed that $96.14 \%$ of the patients were relaxed following the pre operative visit by the anaesthetist (Table 11).

\section{Conclusion}

The preoperative visit to patient by the anaesthetist was grossly below the recommended standards.

\begin{tabular}{|l|c|c|}
\hline & $\begin{array}{c}\text { RCOA } \\
\text { Recommendation }\end{array}$ & $\begin{array}{c}\text { Our } \\
\text { Audit }\end{array}$ \\
\hline $\begin{array}{l}\text { Seen by anaesthetist } \\
\text { before surgery }\end{array}$ & $100 \%$ & $95 \%$ \\
$\begin{array}{l}\text { Self introduction } \\
\text { done by anaesthetist }\end{array}$ & $100 \%$ & $54.03 \%$ \\
$\begin{array}{l}\text { Patient history taken } \\
\text { by anaesthetist }\end{array}$ & $100 \%$ & $95 \%$ \\
$\begin{array}{l}\text { Fasting instructions } \\
\text { given }\end{array}$ & $100 \%$ & $94.39 \%$ \\
$\begin{array}{l}\text { Awareness of type of } \\
\text { anaesthesia before } \\
\text { surgery } \\
\begin{array}{l}\text { Awareness of modes } \\
\text { of postoperative } \\
\text { analgesia }\end{array}\end{array}$ & $100 \%$ & $35.44 \%$ \\
\hline
\end{tabular}




\begin{tabular}{|c|c|c|}
\hline & $\begin{array}{c}\text { Sri } \\
\text { Lankan } \\
\text { Audit } \\
\text { (Urban } \\
\text { Setting) }\end{array}$ & $\begin{array}{l}\text { Our Audit } \\
\text { (Peripheral } \\
\text { setting) }\end{array}$ \\
\hline $\begin{array}{l}\text { Percentage satisfaction of } \\
\text { preoperative visit more } \\
\text { than } 50 \%\end{array}$ & $63.4 \%$ & $94.38 \%$ \\
\hline $\begin{array}{l}\text { Sufficient time spent with } \\
\text { patient }\end{array}$ & $16.5 \%$ & $90.88 \%$ \\
\hline $\begin{array}{l}\text { Patient's questions } \\
\text { answered by anaesthetist }\end{array}$ & $95 \%$ & $83.86 \%$ \\
\hline $\begin{array}{l}\text { Satisfied with the } \\
\text { explanation of anaesthetic } \\
\text { procedure }\end{array}$ & $27.3 \%$ & $42.1 \%$ \\
\hline $\begin{array}{l}\text { Patient became more } \\
\text { anxious after } \\
\text { anaesthetist's visit }\end{array}$ & $6.5 \%$ & $3.86 \%$ \\
\hline
\end{tabular}

In spite of the shortcomings compared to the Royal College of Anaesthetists recommendations, $94.38 \%$ of patients had a percentage satisfaction of more than $50 \%$. This shows that probably patient expectations in Sri Lanka are different, and this difference is greater in peripheral areas than in urban areas. Patient dissatisfaction can be minimized, if the preoperative assessment and intraoperative management is done by the same anaesthetist.

\section{References}

1. Guidelines for the provision of Anaesthetic services - key points on the provision of Anaesthetic services. RCOA, 2004

http://www.rcoa.ac.uk/docs/GPAS.pdf

2. Pre-operative assessment and patient preparation the role of the anaesthetist - Introduction. AAGBI, 2010.

http://www.aagbi.org/sites/default/files/preop2010. pdf

3. Conway JB, Goldberg J, Chung F. Preadmission anaesthesia consultation clinic. Can J Anaesth. 1992 Dec; 39(10):1051-7. http://dx.doi.org/10.1007/BF03008374

PMid:1464132

4. TCMGPG Cooray. Audit to evaluate the patients view, regarding the pre operative visit of the patients by the anaesthetist. Sri Lankan Journal of

Anesthesiology. Vol.19 (1) 2011;.39-42

5. Consent for Anesthesia - Recommendations.

AAGBI,London 2006.

http://www.aagbi.org/publications/guidelines/docs/co nsent06.pdf

\section{THE COLLEGE OF ANAESTHESIOLOGISTS OF SRI LANKA}

\section{FREE PAPERS : SASHIDARAN PRIZE}

The rules of the competition are:

1. Open to all medical practitioners holding an appointment in Anaesthesia.

2. Duration of the presentation must be no longer than 15 minutes.

3. The work in whole or in part should not have been published elsewhere.

4. The full text of the paper with an abstract of not more than 200 words should be submitted before the closing date.

5. The College council shall appoint a committee to make a decision as to whether the papers will be accepted for oral or poster presentation. The decision of this committee as to the mode of presentation and questions relating to eligibility shall be final.

6. A panel of judges shall decide on the award of the prize.

7. The decision of the panel of judges in all matters relating to the competition including questions relating to eligibility shall be final.

8. The prize will not be awarded if the Judges decide the presentation is not up to standard.

9. The first right of publication of the entries submitted lies with the Editor of the College of Anaesthesiologists of Sri Lanka.

The closing date for the 2013 competition is $\mathbf{3 1} \mathbf{1}^{\text {st }}$ October 2012. The abstract and the full text of the paper should reach the Secretary of the College before the closing date. 